\title{
Author Correction: Diagnostic value of ultrasound features and sex of fetuses in female patients with papillary thyroid microcarcinoma
}

\author{
Chun-jie Hou ${ }^{1,2}$, Ran Wei ${ }^{3}$, Jing-lan Tang ${ }^{1,2}$, Qiao-hong $\mathrm{Hu}^{1,2}, \mathrm{Hong}$-feng $\mathrm{He}^{1,2}$ \& Xiao- \\ ming $\operatorname{Fan}^{1,2}$
}

Correction to: Scientific Reports https://doi.org/10.1038/s41598-018-26003-5, published online 14 May 2018

The original version of this Article contained an error in Affiliation 1, which was incorrectly given as 'Department of Ultrasound, Zhejing Provincial People’s Hospital, Hangzhou, China'. The correct affiliation is listed below:

Department of Ultrasound, Zhejiang Provincial People's Hospital, Hangzhou, China

This error has now been corrected in the HTML and PDF versions of the Article, and in the accompanying Supplementary information.

(i) Open Access This article is licensed under a Creative Commons Attribution 4.0 International (c) License, which permits use, sharing, adaptation, distribution and reproduction in any medium or format, as long as you give appropriate credit to the original author(s) and the source, provide a link to the Creative Commons license, and indicate if changes were made. The images or other third party material in this article are included in the article's Creative Commons license, unless indicated otherwise in a credit line to the material. If material is not included in the article's Creative Commons license and your intended use is not permitted by statutory regulation or exceeds the permitted use, you will need to obtain permission directly from the copyright holder. To view a copy of this license, visit http://creativecommons.org/licenses/by/4.0/.

(C) The Author(s) 2018

${ }^{1}$ Department of Ultrasound, Zhejiang Provincial People's Hospital, Hangzhou, China. ${ }^{2}$ People's Hospital of Hangzhou Medical College, Hangzhou, China. ${ }^{3}$ Department of General Surgery, Huashan Hospital \& Cancer Metastasis Institute, Fudan University, Shanghai, China. Chun-jie Hou and Ran Wei contributed equally. Correspondence and requests for materials should be addressed to J.-I.T. (email: tangjinglan_85@163.com) 